\title{
THE EFFECT OF PARTICLE SIZE ON GREEN PELLET PROPERTIES OF IRON ORE FINES
}

\author{
Satyananda Patra\#, Aditya Kumar, Rayasam Venugopal \\ Indian Institute of Technology (Indian School of Mines), Dhanbad, Jharkhand, India
}

(Received: October 27, 2017; Accepted: December 5, 2017)

\begin{abstract}
Recently, the grade of iron ore deposits has deteriorated and further development of low grade deposits is desired. Presently, the most effective and often followed route taken to utilize such deposits is the provision of beneficiation plants for upgrading iron ore and pelletizing plants for agglomerating. The iron ore fines cannot be directly used in the blast furnace as they severely reduce the permeability of the blast furnace bed and bring down the efficiency of the furnace. To overcome this, agglomeration of high grade iron ore fines is done to serve as blast furnace burden. Both the beneficiation and pelletization techniques are key process in utilization of low grade iron ores. This study deals with the beneficiation and agglomeration of the low grade iron ore; up to the extent such that it becomes an ideal blast furnace feed. Effect of particle size on pellet quality during pellet making has also been aimed and studied along with the development of flowsheet for beneficiation of low grade iron ore.
\end{abstract}

Key words: iron ore; beneficiation; agglomeration; pelletization.

\section{Introduction}

Iron and steel industry is considered the backbone of industrial development. The mining of iron ore has a prime importance among all the minerals mined in India $[1,2]$. In recent years, Government of India (GoI) has stipulated a rule to use iron ore up to $45 \%$ Fe not to dump fines and slimes as waste, so to conserve the limited reserves of good quality and to increase the usage of low grade iron ore in the blast furnace feed mix. With the increase in mechanized mining activity and the soft and friable nature of the iron ores, the generation of fines and ultra-fines has been steadily increasing [3 - 5].

In addition to this, the steps involved in beneficiation process, handling and transportation operation generate fines and ultra-fines. These fines and ultra-fines can be efficiently used for the production of iron and steel, if used in the form of pellets or sinters, either directly or after beneficiation [3].

The most commonly employed agglomeration technique is pelletization, wherein a mixture of iron ore, water and binder is rolled in a mechanical disc or drum to produce agglomerates (green balls or wet pellets) [6 - 8].

Pelletization is the unit operation of agglomerating iron bearing mineral fines (generally below $150 \mu \mathrm{m}$ with 65-80 \% passing $40 \mu \mathrm{m})$ by tumbling in horizontal rotating drums or inclined discs, [9 - 14] and the pellets are approximately spherical lumps formed by this process with the help of water and binder, on subsequent induration at $1300^{\circ} \mathrm{C}[6,8,9,13,15-20]$. Binders, during

\#Corresponding author:: spsatyananda05@gmail.com

*A part of this study was presented at the $49^{\text {th }}$ International October Conference on Mining and Metallurgy (IOC 2017), organized by University of Belgrade, Technical faculty in Bor, from $18^{\text {th }}$ to $21^{\text {st }}$ October 2017, Hotel Jezero, Bor Lake, Serbia. 
agglomeration, are added into the iron ore fines to improve the pellet properties and impart strength to the pellets during wet, dried and indurated conditions [7 - 10, 19, 21].

Pelletization involves size enlargement of iron ore fines in presence of binders and moisture in critical amount by forming green pellets followed by drying and firing at high temperature for providing strength to green pellet. The green pellet quality significantly affects the fired pellet quality. Bentonite is the most commonly used binder in iron ore pelletization. It not only controls the moisture in iron concentrate but also remarkably improves physical properties of the pellets [22].

Many researchers attempted to find suitable pellet production systems to achieve production of stronger pellets using either alternative binders or new methods against the conventional ones [15]. The parameters which affect the pelletization process are moisture content, drum or disc inclination, fineness of feed, rotation speed of drum or disc, balling time, type, addition amount and viscosity of binders, etc. [8, 13, 23 - 25].

The most important iron ore pelletization parameters that affect the agglomeration are wetting-nucleation, consolidation - growth and attrition-breakage [26, 27]. This paper outlines the upgrading process as well as pelletization of iron ore fines and the influence of particle size on the green pellet properties.

\section{2. Materials and Methodology}

\subsection{Sampling and Characterization}

Approximately $50 \mathrm{~kg}$ of iron ore fines was collected and after sampling was carried out, particle size analysis was done. Iron ore sample belongs to the Gua mines, located Pashchimi Singhbhum District in the Indian state of Jharkhand. Particle size analysis was carried out using sieve shaker. Result of particle size analysis is given in Figure 1.

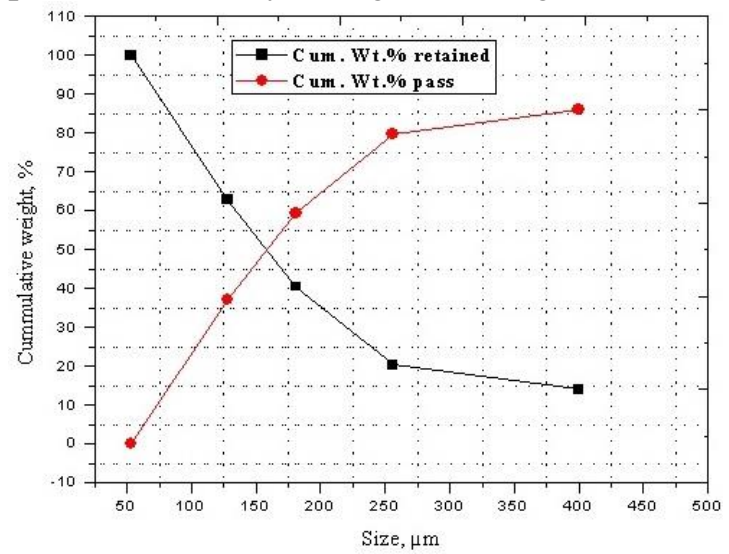

Figure 1. Graphical representation of feed size analysis

After sampling and particle size analysis, chemical analysis was performed for the Fe, $\mathrm{Si}$ and $\mathrm{Al}$ content from the head sample. Then chemical analysis for each size fractions were performed for each individual size fraction illustrated in Table 1 and chemical analysis for head sample illustrated in Table 2 .

Microscopic study of iron ore polished section revealed that hematite is surrounding by goethite. Hematite having major content is disseminated by very small amount of clay and quartz. Figure 2 (a) revealed that goethite surrounded by micro platy hematite with less amount of clay, Figure 2 (b) represents goethite associated in coloform structure with clay and hematite. In case of Figure 2 (c) \& 2 (d) some free iron ore particle having goethite with major content, comparatively high proportion hematite and negligible amount of magnetite was noticed. It was also pointed out that in some section all minerals were found to be associated with each other, due to finely dissemination of gangue particle inside iron ore particles. Figure 2 (d) shows goethite distributed unevenly with hematite and clay, while Figure 2 (d) indicates hematite patches of goethite in ropy shaped clayey matrices. 
Table 1. Fraction wise chemical analysis

\begin{tabular}{|c|c|c|c|c|c|}
\hline Size, $\mu \mathrm{m}$ & Weight, $\%$ & $\mathrm{Fe}, \%$ & $\mathrm{Al}_{2} \mathrm{O}_{3}, \%$ & $\mathrm{SiO}_{2}, \%$ & Loss on ignition, \% \\
\hline$(-300+250)$ & 14.05 & 54.39 & 6.6 & 5.38 & 9.88 \\
\hline$(-250+212)$ & 6.32 & 55.50 & 6.03 & 4.8 & 9.1 \\
\hline$(-212+150)$ & 20.11 & 56.61 & 5.27 & 4.13 & 8.6 \\
\hline$(-150+106)$ & 22.36 & 57.72 & 4.85 & 3.06 & 6.75 \\
\hline$(-106+0)$ & 37.16 & 59.94 & 4.45 & 2.6 & 5.9 \\
\hline
\end{tabular}

Table 2. Chemical analysis of head sample

\begin{tabular}{|c|c|c|c|}
\hline $\mathrm{Fe}, \%$ & $\mathrm{Al}_{2} \mathrm{O}_{3}, \%$ & $\mathrm{SiO}_{2}, \%$ & Loss on ignition, \% \\
\hline 57.6 & 5.29 & 3.12 & 8.92 \\
\hline
\end{tabular}
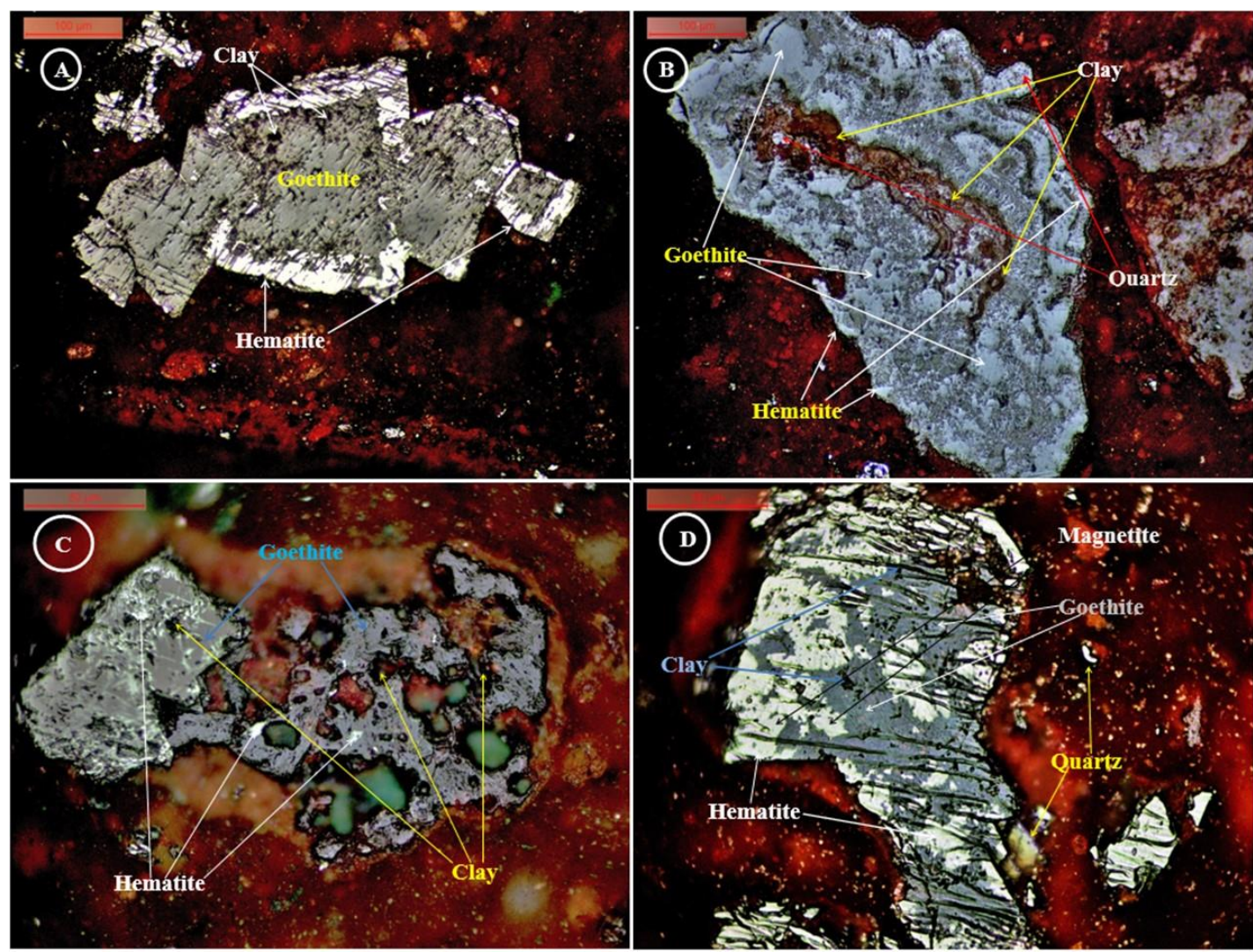

Figure 2. Optical microphotographs of bulk iron ore (A) Revealed that goethite surrounded by micro platy hematite with less amount of clay, (B) Represents goethite associated in coloform structure with clay and hematite, (C) Goethite distributed unevenly with hematite and clay, (D) Indicates hematite patches of goethite in ropy shaped clayey matrices

Scanning Electron Microscopic (SEM) analysis was performed using a FEI 430 Nova Nano-SEM, equipped with a tungsten filament coated with zirconium oxide. The acceleration tension was kept at $15 \mathrm{kV}$ for all the measurements. The results of the SEM studies of iron ore fines are shown in Figure 3. 


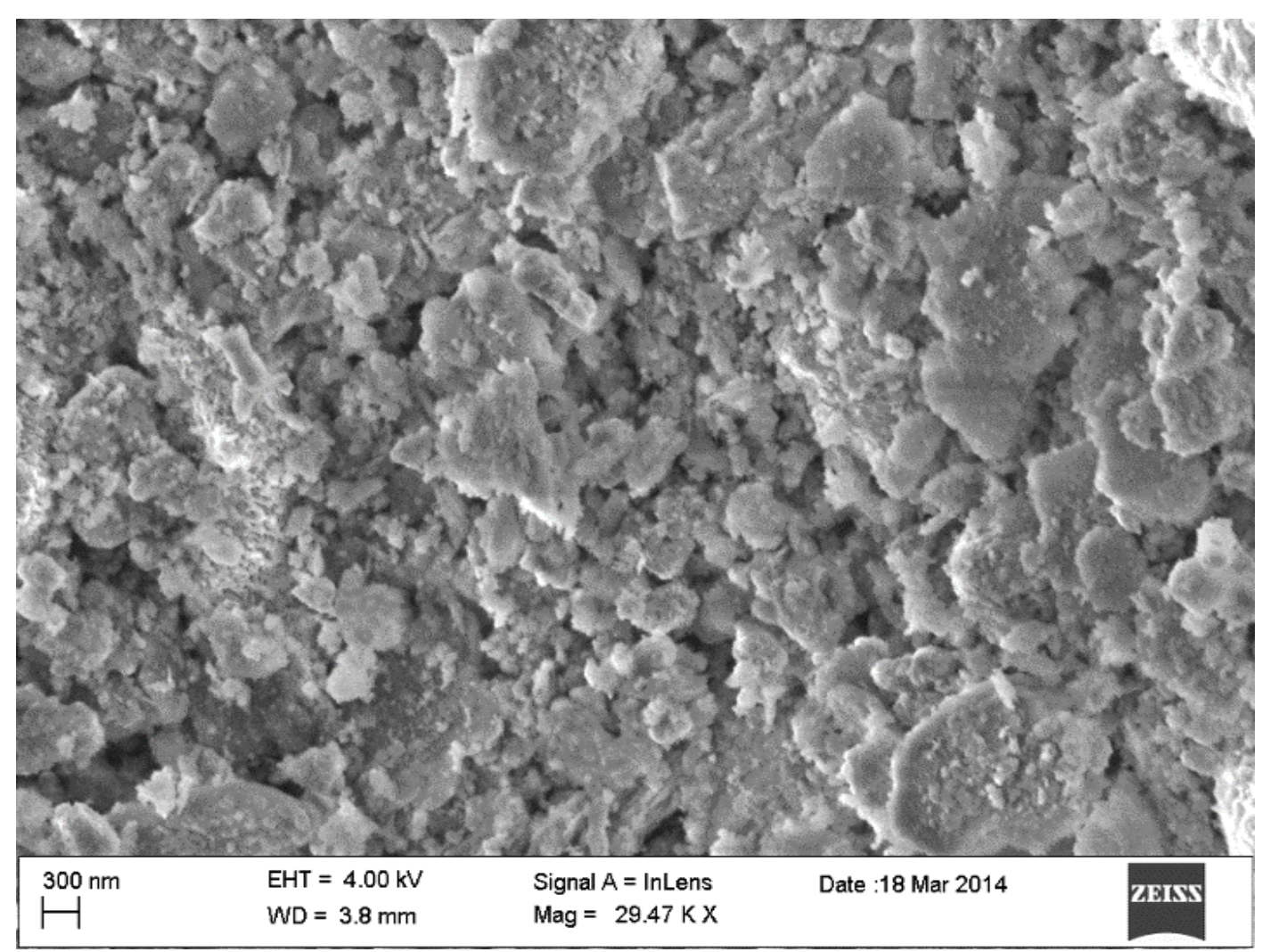

Figure 3. SEM analysis revealed that hematite and goethite are intricately appeared at finer fraction with some amount of quartz

SEM analysis shows that Hematite and goethite grains are stacked upon one another. SEM studies indicate that thin platy shapes of hematite and goethite are associated with each other. Hematite grains are stacked upon one another with equivalent amount of goethite. The SEM results also confirm the presence of iron and minor amount of aluminium hydroxide phase with quartz at very fine grains.

\subsection{Sample preparation:}

After carrying out analysis on feed material, sample was prepared for experimental purpose. Sampling was carried out on $30 \mathrm{~kg}$ of sample and mixed thoroughly before beneficiation. Process flowsheet for method is illustrated in Figure 4.

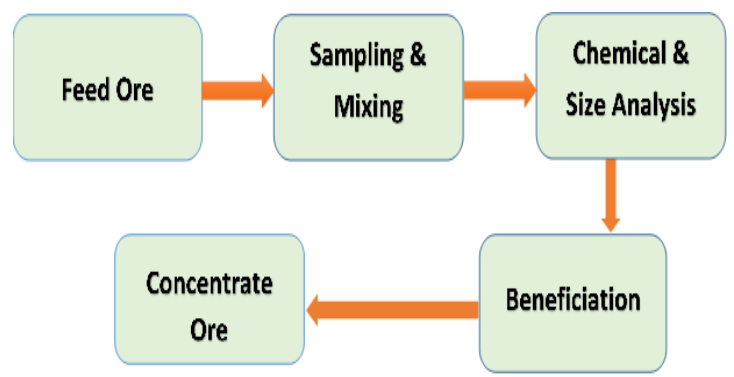

Figure 4. Pellet feed sample preparation flowsheet

Beneficiation was carried out after characterization to upgrade the ore, then sampling was done two times to get four products of $3 \mathrm{~kg}$ each. 
To study the effect of particle size on pellets, feed was prepared for four different size ranges. These size ranges taken for pellet making is illustrated in Table 3 .

Table 3. Experimental Parameter (different feed size)

\begin{tabular}{|l|c|c|c|}
\hline \multicolumn{4}{|c|}{ Different Pellet Feed Size, $\mu \mathrm{m}$} \\
\hline-106 & -75 & -52 & -44 \\
\hline
\end{tabular}

These four products were further ground to finer size for further pelletization studies. All the four products were ground. Again size analysis of ground product was carried out by MASTERSIZER Hydro-2000MU (A) with absorption of 0.03 at a particle size range of $0.02 \mu \mathrm{m}$ to $2000 \mu \mathrm{m}$. The particle size of iron ore concentrate (pellet feed) were carried out by particle size analyzer, are given in Figure 5.

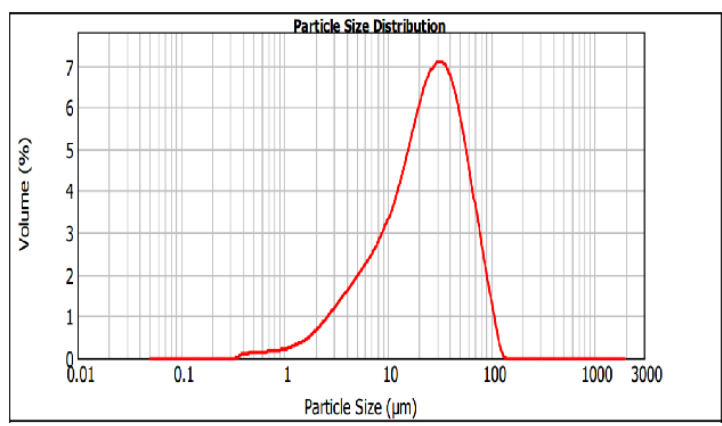

Figure 5. Particle size analysis of pellet feed

The results indicate that the $100 \%$ passing size of this sample is $75 \mu \mathrm{m}$. More than $90 \%$ of the materials are below $45 \mu \mathrm{m}$. At the final preparation of material for pelletization feed all the ground product were divided in to four fractions, i.e. $-106 \mu \mathrm{m},-75 \mu \mathrm{m},-52 \mu \mathrm{m}$ and $-44 \mu \mathrm{m}$. Each sample was then sieved to their respective sizes of $-106 \mu \mathrm{m}, 75 \mu \mathrm{m}, 52 \mu \mathrm{m}$ and $44 \mu \mathrm{m}$. Now these four samples were readied for pellet preparation with the addition of binders. After addition of binders, each sample was thoroughly mixed to attain homogeneity of binders among given sample.

\section{Experimental Set-up}

Beneficiation studies were carried out using gravity (Wilfley table, Figure 6) and magnetic separation (WHIMS, Figure 7) techniques followed by fine grinding.

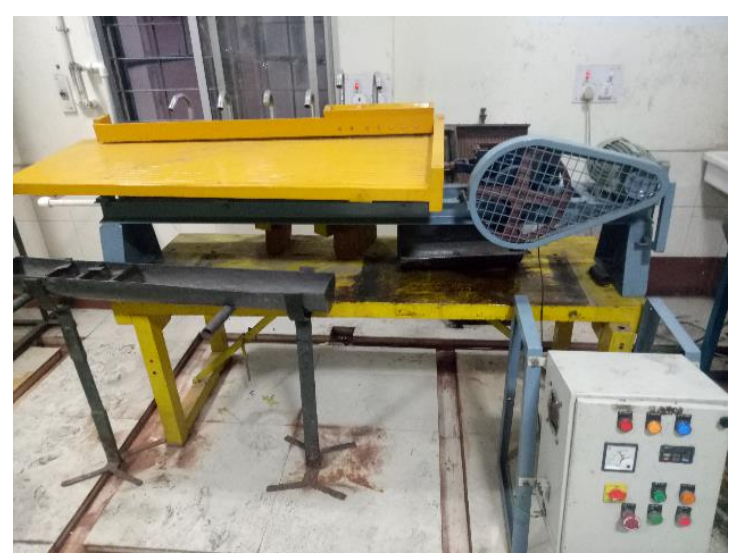

Figure 6. Image of Laboratory Scale Wilfley Table

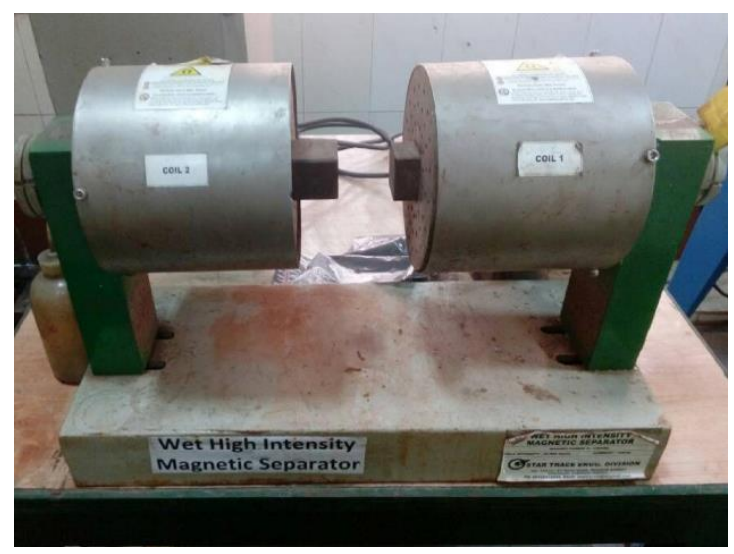

Figure 7. Laboratory scale Wet High Intensity Magnetic Separator (WHIMS)

Parameters taken for different processes mentioned below:

Wilfley Table:

- Water Flow Rate 5 Liters/minute

- Operating Angle of Inclination $5^{\circ}$

- Pulp Density (Solid/Liquid Ratio) $25 \%$ Feed size $-300 \mu \mathrm{m}$ 
Wet High Intensity Magnetic Separator (WHIMS):

- Matric Used Steel Ball

- Current $1.5 \mathrm{~A}$

- Intensity 12000 Gauss

- Pulp Density (Solid/Liquid Ratio) $15 \%$

- Feed size $-300 \mu \mathrm{m}$.

Pelletization experiments were carried out on a disc pelletizer having a diameter of $40 \mathrm{~cm}$ and a rim height of $15 \mathrm{~cm}$. Iron ore sample of $1 \mathrm{~kg}$ each was mixed with bentonite at different proportions prior to the pelletization study. Moisture was added slowly and continuously. Pelletization time $20 \mathrm{~min}$, rotation per minute (RPM) 35, binder (bentonite) dosage $1 \%$, moisture $10 \%$, and disc inclination $42 \circ$ were fixed, after preliminary studies. The quality of pellets was tested for $\%$ yield of $+9 \mathrm{~mm}$ pellets, mean drop number (MDN) and green compressive strength (GCS).

\section{Results and Discussion}

\subsection{Beneficiation Studies}

Ore sample of $-300 \mu \mathrm{m}$ size was selected for experiment purpose and subjected to beneficiation. First stage cleaning was carried out using Wilfley Table on $15 \mathrm{~kg}$ of sample. Sample ore was upgraded from $57.71 \% \mathrm{Fe}$ to $63.37 \% \mathrm{Fe}$. Owing to poor yield and $\mathrm{Fe}$ recovery in Stage 1 of cleaning, Stage 2 of cleaning was required to improve the recovery of Fe. Many Fe were washed away to tailings during the $1^{\text {st }}$ Stage of cleaning. To recover those washed $\mathrm{Fe}$ in tailings of $1^{\text {st }}$ Stage, tailings of Wilfley table were again ground to below 45 micron and then treated by WHIMS. During this stage of beneficiation, WHIMS upgraded the slurry from $45.98 \% \mathrm{Fe}$ to $62.03 \% \mathrm{Fe}$. Concentrate obtained from both stages of cleaning were mixed and bended to give final ore for pellet making. Grade of blended ore was $62.7 \% \mathrm{Fe}$ at a yield of $71 \%$ with total $\mathrm{Fe}$ recovered were $77.1 \%$. Final flowsheet of the process is illustrated through Figure 8.

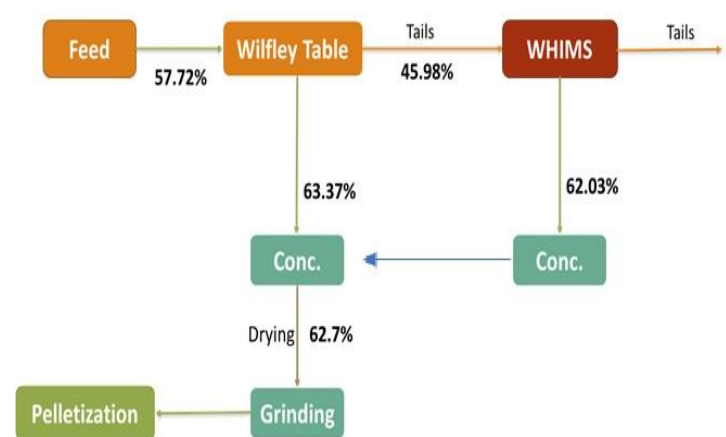

Figure 8. Flow sheet of the overall beneficiation process

\subsection{Pelletization studies}

After beneficiation and grinding, samples were prepared for pellet formation at four different feed sizes for pellet. Pellet balls made from four different feed sizes were then evaluated for: Green Compressive Strength (GCS), Mean Drop Number (MDN) and Yield of $+9 \mathrm{~mm}$ pellets. Analysis of pellet balls formed is illustrated in Table 4.

Table 4. Experimental results

\begin{tabular}{|c|c|c|c|}
\hline $\begin{array}{c}\text { Pellet feed size, } \\
\mu \mathrm{m}\end{array}$ & $\begin{array}{c}\text { Green Compressive } \\
\text { Strength, Kg per pellet }\end{array}$ & $\begin{array}{c}\text { Mean Drop No., } \\
\text { Numbers. }\end{array}$ & $\begin{array}{c}\text { Yield of }+9 \mathrm{~mm} \\
\text { pellets, } \%\end{array}$ \\
\hline-106 & 1.01 & 7.5 & 76 \\
\hline-75 & 1.27 & 9.2 & 88 \\
\hline-52 & 1.64 & 12.1 & 98 \\
\hline-44 & 2.01 & 13.6 & 100 \\
\hline
\end{tabular}


Experimental data from Table 4, supports the theory that finer size used during pellet making improves the quality and performance of the already formed pellet balls. Finer grains in feed accounts to more surface area. Due to increased surface area in finer feed size, inter particle force acting the particles increases which subsequently enhances strength of the pellets. From Figure 9(c), it is observed that, finer size used in pellet making increases the compressive strength of pellet and can withhold higher load. Another benefit of using finer sized grain in pellet making is increased compressive strength, due to closely packed finer particles. The resultant bonding is stronger because of Van-der wall's force, capillary forces and wettability factor.

From Figure 9(b), it is clearly illustrated that drop number of pellet increases with the increase in finer grain number contributed to pellet making whereas Figure 9(a) shows that bigger uniformly sized pellets can be produced from more finer size particle during green pelletization. Variance in pellet radius decreases and most of the pellets respond to the finer material size in feed with increasing radius of pellet.
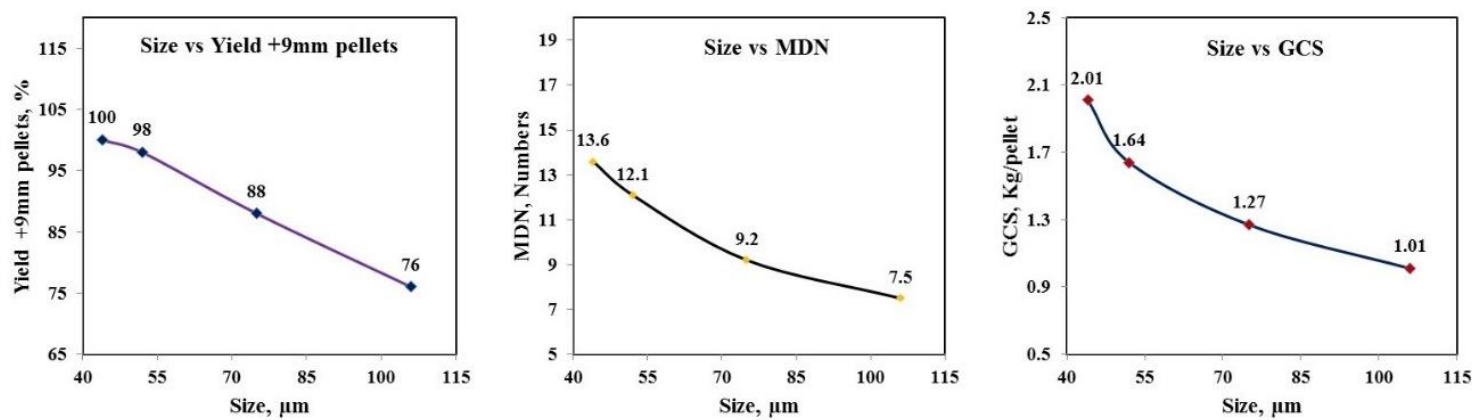

Figure 9. (a) Performance curve of Yield of $+9 \mathrm{~mm}$ pellet vs Feed size, (b) Performance curve of Mean Drop Number vs. feed size and (c) Performance curve of GCS vs feed size

\section{SEM Analysis of Dry Pellets}

Cross section of green pellet was prepared then analyzed through SEM, microphotographs were taken for pellets of feed size fractions i.e. $44 \mu \mathrm{m}, 52 \mu \mathrm{m}, 75 \mu \mathrm{m}$ and $106 \mu \mathrm{m}$ respectively to study the characteristics of the pellet. The results of the SEM analysis of dry pellets are given in Figure 10 and 11.

The results in Figure $10(1 \&$ \&a and $2 \&$ 2a) shows the SEM analysis of pellets for feed size of $106 \mu \mathrm{m}$ and $75 \mu \mathrm{m}$, which represents porous structure associated with coarser size fraction of feed material, when the feed material is coarser, it means it appears more interstitial space among the particle which allow water molecule to pass and attach with the material and binder to bind them together. More interstitial space indicated more porosity, due to which the packing of material is loose, water with binder cannot bind the material properly, as a result the bonding of particle is weak, which implies acceptable size of the pellet but higher porosity, low strength and drop number.

Figure $11(3 \& 3 a$ and $4 \& 4 a)$ shows the SEM microphotographs of pellets for feed size fractions of $52 \mu \mathrm{m}$ and $44 \mu \mathrm{m}$. Finer fraction of feed material results close packing. The water molecules surpass to the surface of the pellet and it also helps to form monolayer at the surface of the pellet, which gives maximum strength to the pellet. Though the monolayer gives strength to the pellet to prevent cracking and breakage. 


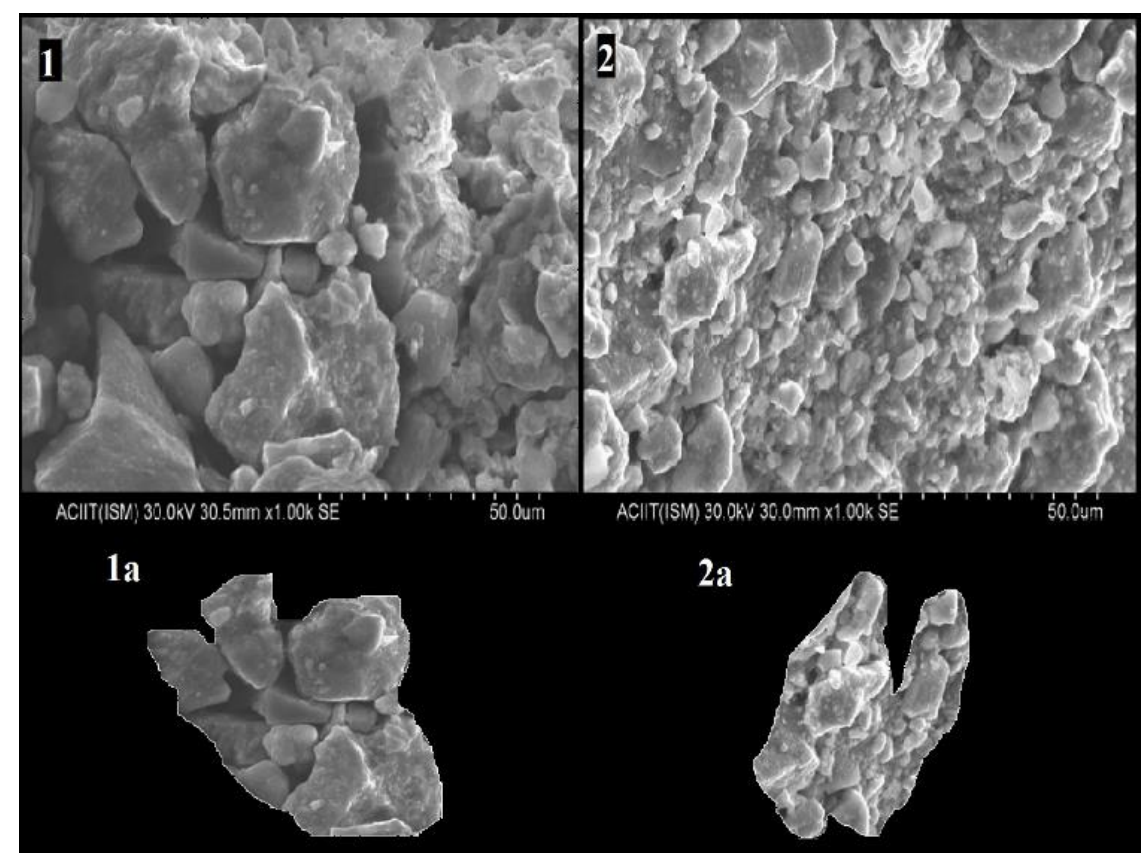

Figure 10. 1 \& 1a shows porous structure associated with coarser fractions whereas $2 \& 2 \mathrm{a}$ shows closely packed with iron ore particles. Presence of porosity is higher in case of coarser size

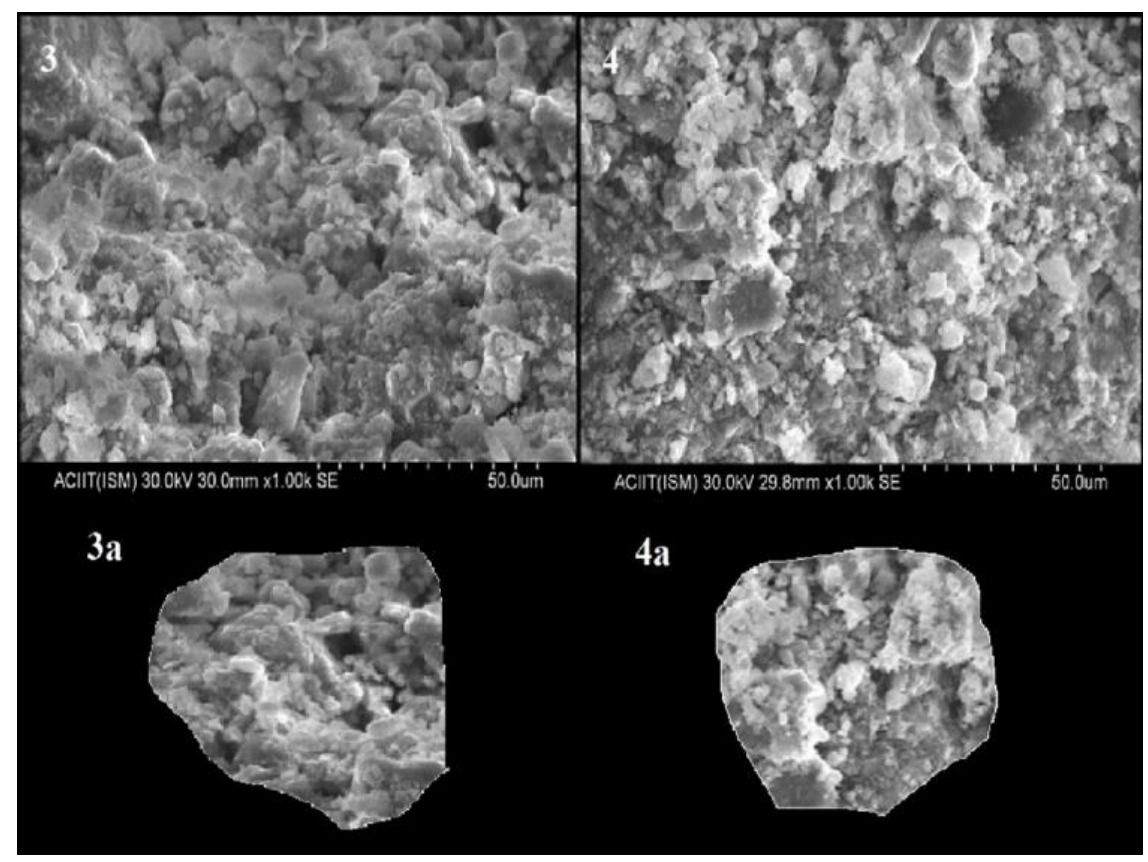

Figure 11. In Figure $3 \& 3 a$ and $4 \& 4 a$, it is distinguished that although pellet size is acceptable in both the cases, because of its close packing structure leads to strong bonding 
It is distinguished that although pellet size is acceptable in both the cases, but presence of porosity is lower in case of finer fractions due to close packing of the particle. High porosity leads to fill the interstitial spaces with water which subsequently causes weak bonding, hence pellet with moderate strength is obtained.

Porosity analysis was carried out using conventional method to evidence the SEM analysis results. Approximately $13.1 \%$ and $8.36 \%$ of porosity were analyzed for pellets of feed size $106 \mu \mathrm{m}$ and $75 \mu \mathrm{m}$. Similarly, approximate porosity of pellets for feed size $52 \mu \mathrm{m}$ and $44 \mu \mathrm{m}$ are $7.05 \%$ and $5.6 \%$ respectively. The results of porosity are given in Figure 12.

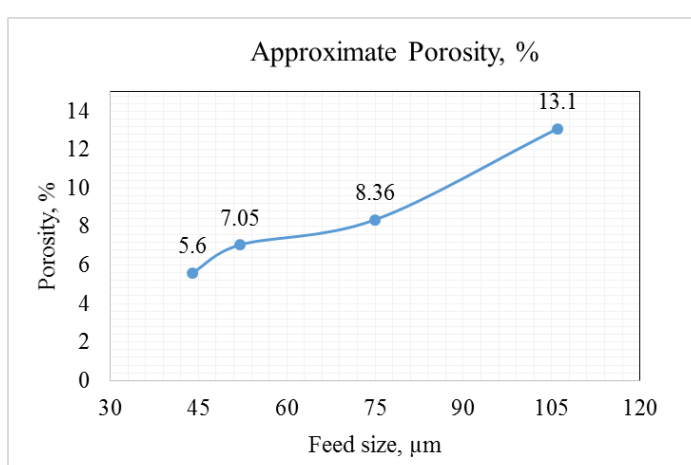

Figure 12. Results of porosity for pellets of feed size fractions $106 \mu \mathrm{m}, 75 \mu \mathrm{m}, 52 \mu \mathrm{m}$ and $44 \mu \mathrm{m}$ respectively

\section{Conclusions}

From the above study it can be concluded that:

- Characterization studies comprising of size wise chemical analysis, optical microscopic studies and SEM analysis shows the presence of hematite, goethite with high alumina content. Thus, subsequent beneficiation operation was processed to achieve pellet grade iron ore.
- Although coarser sized particles form pellets of required size but these pellets are unable to meet the requirements, due to high porous composition of particles, low strength and drop number, which is caused by high interstitial space.

- Improvement in pellet strength and drop number is achieved in intermediate sized particles $(-75$ and $52 \mu \mathrm{m})$ but yield of $+9 \mathrm{~mm}$ pellet is only $88 \%$, which is a major reason of generating circular load i.e. recycle of material. It can also be a major problem for downstream process.

- Further it is observed that pellets formed from very fine sized particle (52 and 44 $\mu \mathrm{m})$ inherits high strength and drop number with maximum yield. But producing pellets from $-44 \mu \mathrm{m}$ sized particle is not preferable in large scale operation as grinding of particles such extent results into more energy consumption and production cost. It may also cause environmental threaten due to dust production.

So it may be concluded that production of pellets from $-44 \mu \mathrm{m}$ is neither economic nor environmentally viable option. Thus $-52 \mu \mathrm{m}$ feed size is optimum for the production of desired grade pellets.

\section{Acknowledgements}

The authors gratefully acknowledge the technical support extended by Central Research Facility - IIT(ISM), Dhanbad. Authors would like to thank all technical staff of Fuel and Mineral Engineering Department, for their support during the experimental work.

\section{References}

[1] Kumar, P., Sahoo, B.K., De, S., Kar, D.D., Chakraborty, S., Meikap, B.C. 
(2010) Iron ore grindability improvement by microwave pre-treatment. Journal of industrial and engineering chemistry, 16 (5), 805-812.

[2] Kingman, S., Jackson, W. K., Bradshaw, S. M., Rowson, N. A., Greenwood, R., (2004) An investigation into the influence of microwave treatment on mineral ore comminution. Powder technology, 146 (3), 176-184.

[3] Mahiuddin. S., Bondyopadhway. S., Baruah. J. N. (1989) A study on the beneficiation of Indian iron-ore fines and slime using chemical additives. International Journal of Mineral Processing, 26 (3-4), 285-296.

[4] Sen, P., Mishra, D.D. (1972) The problem of the iron ore fines in India. NML Tech. Journal, 14, 47-55.

[5] Chaurasia, R.C., Suresh, N. (2016) Application of artificial neural network to study the performance of multi-gravity separator (MGS) treating iron ore fines. Particulate Science and Technology, 110.

[6] Sivrikaya, O., Arol, A.I. (2012) Evaluation of low grade iron ore deposit in Erzincan-Turkey for iron ore pellet concentrate production. Physicochemical Problems of Mineral Processing, 48 (2), 475-484.

[7] Meyer, K. (1980) Pelletizing of Iron ore, Springer-Verlag Berlin, Dusseldorf, Germany.

[8] Iveson, S.M., Litster, D., Hapgood K., Ennis B.J. (2001) Nucleation, growth and breakage phenomena in agitated wet granulation processes: a review, Powder Technology, 117 (1), 3-39.

[9] Sivrikaya, O., Arol A.I. (2014) Alternative Binders to Bentonite for Iron Ore Pelletizing - Part II: Effects On Metallurgical And Chemical Properties. 2014, HOLOS.
[10] Bhuiyan, I.U., Mouzon, J., Forsmo, S.P.E., Hedlund, J. (2011) Quantitative image analysis of bubble cavities in iron ore green pellets. Powder Technology, 214, 306-312.

[11] Forsmo, S.P.E., Apelqvist, A.J., Björkman, B.M.T., Samskog, P.O., (2006) Binding mechanisms in wet iron ore green pellets with a bentonite binder, Powder Technology, 169, 147-158.

[12] Forsmo, S.P.E., Forsmo, S.E., Samskog, P.O., Björkman, B.M.T. (2008) Mechanisms in oxidation and sintering of magnetite iron ore green pellets. Powder Technology, 183, 247-259.

[13] Abouzeid, A.Z.M., Seddik, A.A. (1981) Effect of Iron Ore Properties on its Balling Behaviour. Powder Technology, 29, $233-441$.

[14] Sastry, K.V.S., Fuerstenau, D.W. (1973) Mechanisms of Agglomerate Growth in Green Pelletization. Powder Technology, 7, 97-105.

[15] Sivrikaya, O., Arol, A.İ. (2013) An investigation of the relationship between compressive strength and dust generation potential of magnetite pellets. International Journal of Mineral Processing, 123, 158-164.

[16] Sivrikaya, O., Arol, A.I.,(2010) Use of Boron Compounds as Binders in Iron Ore Pelletization, The Open Mineral Processing Journal, 25 (3), 25-35.

[17] Sastry, K.V.S., Dontula, P., Hosten, C. (2003) Investigation of the layering mechanism of agglomerate growth during drum palletization. Powder Technology, 130, 231-237.

[18] Kawatra, S.K., Ripke, S.J. (2003) Laboratory studies for improving green ball strength in bentonite-bonded magnetite concentrate pellets. Int. J. Miner. Process., 72, 429-441.

[19] Iveson, S.M., Wauters, P.A.L., Forrest, S., Litster, J.D., Meesters, G.M.H., 
Scarlett, B. (2001) Growth regime map for liquid-bound granules: further development and experimental validation. Powder Technology, 117, 83-97.

[20] Abouzeid, A.Z.M., Seddik, A.A., ELSinbawy, H.A. (1979) Pelletization Kinetics of an Earthy Iron Ore and the Physical Properties of the Pellets Produced. Powder Technology, 24, 1979, 229-236.

[21] Qiu, G., Jiang, T., Li, H., Wang, D. (2003) Functions and molecular structure of organic binders for iron ore palletization. Colloids and Surfaces A: Physicochem. Eng. Aspects, 224, 11-/22.

[22] Guanzhou, Q., Jiang, T., Li, H., Wang, D. (2003) Functions and molecular structure of organic binders for iron ore palletization. Colloids and Surfaces A: Physicochem. Eng. Aspects, 224, 11-22.

[23] Ennis, B. J., Li, J., Robert, P. (1990) The influence of viscosity on the strength of an axially strained pendular liquid bridge. Chemical Engineering Science, 45 (10), 3071-3088.

[24] Ennis, B.J., Tardos, G., Pfeffer, R. (1991) A micro-level-based characterization of granulation phenomena. Powder Technology, 65 (1-3), 257-272.

[25] Paul, M., Tardos, G. (1999) Scale-up of agglomeration processes using transformations. KONA Powder and Particle Journal, 17 (0), 64-75.

[26] Martin, B., Hyman, D. (1971) Rotary drum granulation. An experimental study of the factors affecting granule size. Industrial \& Engineering Chemistry Fundamentals, 10 (2), 212-219.

[27] Tardos, G. I., Khan, M.I., Mort, P.R. (1997) Critical parameters and limiting conditions in binder granulation of fine powders. Powder Technology, 94 (3), 245-258. 